particular faults, some minsr, some more scrious, can be found.

It is doubtful if a book devoted solely to the electrical activity of the nervous system can today provide a balanced account of what is known about the workings of the brain and neuromuscular systems. The early chapters on the nerve impulse and synaptic mechanisms are frequently repetitive, and as the account given is largely that of earlier editions the presentation loses some of the clarity which more recent advances have brought. For example, the voltage clamp studies of Hodgkin and Huxley are not mentioned.

The succeeding chapters discuss sensory systems, the reticular formation and the electroencephalogram, and the systems which are concerned with the control of muscle are only mentioned in passing.

There are some misprints and misstatements which could be confusing for students. For example, membrane potentials of tens of $\mathrm{mV}$ in size are frequently given as only tens of $\mu \mathrm{V}$, the synaptic cleft at the neuromuscular junction is stated to be twenty times wider than it is, the ommatidium of the insect eye is described as if it were a single cell, and some postsynaptic potentials are deseribed as lasting for $100 \mathrm{~s}$ rather than $100 \mathrm{~ms}$.

M. C. Brown

\section{ROUTE FINDING IN ANIMALS}

\section{Animal Orientation and Navigation}

Edited by Robert M. Storm. (Proceedings of the Twentyseventh Annual Biology Colloquium, May 6-7, 1966.) (Corvallis: Oregon State University Press, 1967.) $\$ 5$.

The reasons for this colloquium are not clear, but it appears to have had the intention of informing the audience of the present state of knowledge about some aspects of orientation and navigation. The papers given do not read as if they were being delivered to people who knew a great deal about the subject, certainly not to an audience of research workers in this particular field. So the book has to be judged with this in mind, and the absence in some of the chapters of hard data, which can be critically ovaluated, has to be overlooked.

Six papers are included, each with a short discussion after them. Hasler gives a readable résumé of the work on migrating fishes; in the discussion some interesting points about the Pacific salmon movements are brought out. This author repeats at various points in the book the sage advice not to hypothesize in armchairs but to get up out of them and put the theories to experimental test. Ferguson describes some of this work on the use of the sun-compass by anurans, perhaps bedevilling the issue by inventing a nomenclature all his own. Carr discusses the possible adaptive significance of the apparently unnecessary journeys made by turtles from the South American coast to the Ascension Islands and back. Hamilton puts forward his thesis that the V-formation of geese is taken up for navigational reasons, not for ease of llight; he supposes that in this formation, migratory information can be communicated from individual to individual. Bellrose proposes that nonsense orientation in waterbirds is symptomatic of stress conditions- $a$ not at all unreasonable supposition which can be supported from observations on other groups including invertebrates. He wishos that the final blow should be given to the idea that a bird moving in a body of air gets no information from the wind; no wind is ideally smooth and the turbulence will given information about tho wind's direction. The final paper by Norris is a very good roview of the relatively scanty information about the long-distance movements of marine mammals in which he proposes that the primary function of blubber is to act as a food store; heat insulation is secondary.
The tone of the papers is interesting, for the oftenrepeated plea is for more experimentation and yet the sun-compass in one or other of its forms seems to fail to explain so much that recourse is made to many of the once-discarded theories of magnetism and so forth. It may well be that some sort of move--a backward one in a sense-will have to be made in their direction but, again as discussants stressed, it is unlikely that one explanation will save to explain all the phenomena, not even all those shown by one animal. J. D. CARThy

\section{TEXTBOOK ON TIMBER}

\section{Timber: Its Structure and Properties}

By H. E. Desch. Fourth edition. Pp. xviii $+399+65$ plates. (London: Macmillan and Co.; New York: St Martin's Press, 1968.) 100s.

THis book has for years been one of the standard textbooks on wood technology in Great Britain. Before the first edition, there were few which covered the three year TRADA certificate course for which the Institute of Science is now the examining body, and it was obviously written with this in mind.

The great increase in knowledge of wood necessitated new editions, and this, the fourth edition, has attempted to bring the data to the student of timber technology in a format which is readable, knowledgeable and at the same time technically sufficient for a general appreciation of the scientific approach to the use of wood.

Read in this light, this book follows in the steps of its predecessors, but unfortunately it is open to criticism particularly in view of the opening sentence of the preface. Today, the symbols $S 1, S 2$ and $S 3$ are generally used for describing the thickening of the secondary wall and these could have been included in the text if not on the diagrammatic representation of the cell wall structure. It is curious that over the years no one has picked up the anomaly in plate 6, "Typos of Commercial Mahogany". Illustrated are Central American mahogany, Swietenia macrophylla; African mahogany, Khaya ivorensis; and Red Moranti, Shorea spp. Had this been called Philippine or Borneo Mahogany, a name deprecated by BSI, then it would have come under the plate title, but Meranti, a Malayan word, is sold as that and no record has appeared of "Malayan Mahogany" even in the author's authoritative book, Manual of Malayan Timbers.

The inclusion of the chapter on the end-grain structure of hardwoods and general notes on the genera illustrated is an improvement, but while it is difficult to show a true comparison of ray widths by linear methods, care must be taken in using some of these drawings as a means of identification. Although the diffusion mothod of applying preservatives is mentioned, no details as to how this is carried out are given, and the use on page 141 of an outof-date chart for the moisture content of timber for different purposes is somewhat surprising.

The author refers to re-writing "those sections where recent developments have an immediate practical application", yet there is no reference to the flat-plate nailed connectors which are being used to an ever increasing extent over the toothed connector today. There is a tendency today in books of this kind to include the references at the end of each chapter and this would have bəen an improvement. The selected bibliography makes very curious reading in the light of the preface. Under chapter 4, "General Characters", the most up-to-date reference is 1937, and unfortunately there are similar anomalies under other chapter references.

The production, illustrations and presentation of this book comply with the high standards of the publishers, but it is felt that the price of this edition may be 'Neyond the usual run of students.
R. P. Woods 